\title{
A Thermodynamic Review of Recent Developments on the Design Of Solar Air Heaters
}

\author{
Amol Dhande ${ }^{1}$, Prof. G. D. Agarwal ${ }^{2}$ \\ ${ }^{1}$ Lecturer in Mechanical Engineering, Government Polytechnic, Ratnagiri, \\ ${ }^{2}$ Professor, Malaviya National Institute of Technology, Jaipur.
}

\begin{abstract}
The sun has been a powerful presence and force throughout the history of human existence on earth. The solar air heating system is the technology to harness the plenty amount of free available solar thermal energy. This paper reviews and encompasses the technological developments in the field of solar air heater with their applications. Nowadays, hot air is used for domestic, commercial and industrial purposes. Various resources gas, diesel, coal etc, are used to heat the air. The solar air thermal system is designed to meet the energy demands. The size of the systems depends on availability of solar radiation, temperature requirement of customer, geographical condition and arrangement of the solar system, etc. Therefore, it is necessary to design the solar air heating system as per above parameters. The available literature is reviewed to understand the construction, arrangement, applications and sizing of the solar air thermal system. The review is performed to allow a discussion and evaluation of the findings obtained by researchers. The review covers the over view of solar air heater technology, detail description of various types of solar air heaters, solar air heaters with different absorber plate surface geometry to enhance the rate of heat transfer.
\end{abstract}

\section{Keywords: SAH, Baffles, Fins, Heat transfer}

\section{INTRODUCTION}

$\mathrm{T}$ he essence of energy to our society is growing to ensure the quality of life and to smoothly run the other elements of our economy. Several renewable energy technologies are in practice in 21 st century, but many of them are under development. Solar energy is the origin of all forms of energy. In various solar energy applications, the solar air heaters (SAHs) were commonly used as heat exchanger [1].

Some important advantages of solar thermal systems are as follows: they work on noiseless environment, do not produce any unwanted waste such as radioactive materials and are one of clean technologies. They do not produce any toxic waste or radioactive material and are highly credible systems with life span expectation between 20 and 30 years. They are also low maintenance systems. Non-uniform cooling - need innovative absorber design, payback - less efficiency, longer payback period, production and installation cost-expensive and high cost, not suitable for integration with present roof system and need larger space for separate systems (hot water and electricity production) are some disadvantages of solar systems [2].

As stated above that their efficiencies are still lower compared to other systems. Thus, there are many studies on heat transfer enhancement technique of SAHs such as surface treatment, attaching of different shaped baffles or fins, changing of flow directions etc. in the literature. In the recent years, many studies have focused on enhancement of heat transfer in SAHs and 


\section{International Journal of Innovations in Engineering and Science, www.ijies.net}

constructing of high efficiency collectors. Various studies have been undertaken using numerical and experimental methods, while results obtained have been used to calculate energy efficiency of SAHs [3].

The main applications of SAHs are space heating, seasoning of timber, curing of industrial products, and these can also be effectively used for curing/drying of concrete/clay building components. The SAH occupies an important place among solar heating system because of minimal use of materials and cost $[4,5]$. The applications of solar energy to heat the fluids can include drying vegetables, fruits, meats, eggs incubation, and other industrial purposes. SAHs are also used to heat spaces, especially during autumn and spring seasons. The heated air is also useful to preserve the food grains which reduce the spoilage of food [6]. Interest in commercializing concentrating solar technologies has been rejuvenated, after successful implantation in the late-1980s [7].

\section{Classification of Solar Air Heater}

SAHs are classified according to collector cover, absorber materials, shape of absorbing surface, absorber flow pattern, flow shapes, hybrid collectors and their applications. All challenges have focused on heat transfer enhancement inside the SAHs. A classification of SAHs is given in Fig. 1 [8].

Basically, all SAHs can be classified under two categories [9]

1. Air heaters with non-porous absorber plate

2. Air heaters with porous absorber plate.

\subsection{Air Heaters with Non-Porous Absorber Plate}

In this type, the air may flow above or beneath the absorber. Selective coating can be applied to improve collector efficiency. These can be classified as [9]:

1. Conventional air heater,

2. Air heaters with fins,

3. Vee-corrugated air heater,

4. Double exposure heaters,

5. Double flow solar air heater and

6. Two pass solar air heater.

\subsection{Air Heaters with Porous Absorber Plate}

In this type, the air stream flow through the absorber plate.

The porous absorber SAHs can be classified as [9]:

1. Packed bed solar air heater,

2. Overlapped glass plate air heater,
3. Matrix air heater,

4. Honeycomb porous bed air heater and

5. All plastic solar air heaters

2. Construction and Materials Used In Solar Air Heater

The key components of solar air heater are absorber plate, duct, insulation, blower and transparent cover.

2.1 Absorber plate: It is a main element of the system which decide the thermal performance of the system. Absorptivity plays vital role for absorber. Therefore, it is always coated with black paint to absorb maximum solar energy incident on it. The plates are generally made up of galvanized iron, aluminum, cast iron, copper etc.

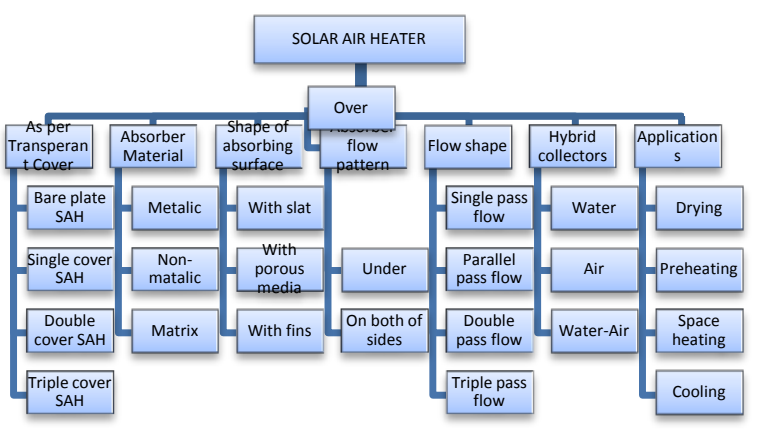

Fig 1- Classification of Solar Air Heaters

2.2 Duct: The supply of fresh air and exhaust of hot air by natural and forced convection is conducted through ducts. Air velocity plays vital role for the selection of duct material. Generally circular and rectangular ducts are preferred. Ducts are manufactured from galvanized iron, steel, fiber coated plastic, aluminium cane etc.

2.3 Insulation: In order to improve the economy of heat loss, insulation is a dominant part of SAH system. It not only serve the purpose of reducing the heat loss through condensation but also assist in maintaining the efficiency and conserve energy. The typical insulations used are wooden block, glass-wool, expanded polystyrene, thermocol etc.

2.4 Blower: It is one of the key component in SAH system as it is responsible for forced circulation. Blower not only improves heat transfer rate but also enhances good flow rate of air. Quantity of air handled plays role while selecting of blower.

2.5 Transparent Cover: It allows entry of solar radiation and prevent infrared energy losses through reradiation. As it is transparent, it reduces convective losses. It must have high transmissivity and largely opaque to long wave length radiations. Glass is the 


\section{International Journal of Innovations in Engineering and Science, www.ijies.net}

preferred material as a transparent cover over polycarbonate, acrylic sheet.

\section{Brief Theory on Solar Air Collector Performance}

Mass flow rate of air is defined as the mass of air which passes through SAH per unit time and is calculated in $\mathrm{kg} / \mathrm{s}$.

$$
m=\rho A v
$$

The heat transfer is the function of specific heat and mass that undergoes temperature change:

$$
Q=m C p(Q o u t-Q i n)
$$

Where, $\mathrm{m}$ is the mass flow rate of air through the heater $(\mathrm{kg} / \mathrm{s}), \mathrm{Cp}$ is the specific heat capacity of air $\mathrm{in}\left(\mathrm{J} / \mathrm{kg}{ }^{0} \mathrm{C}\right)$ and (Tout - Tin) is the temperature difference across the air heater $\left({ }^{0} \mathrm{C}\right)$

The collector efficiency is the most important parameter for expressing the performance of SAH. Solar collector hourly based thermal efficiency is defined as the ratio of energy gained on the collector and the incident solar radiation.

The thermal efficiency of collector is given by,

$$
\eta=m C p(Q \text { out }-Q \text { in }) / I A c
$$

Where $\mathrm{I}=$ Solar radiation and $\mathrm{Ac}=$ area of the collector

\section{II- DESIGNS AND PERFORMANCE IMPROVEMENTS IN SOLAR AIR HEATERS}

Mesut Abuska designed a SAH with conical surface structure on absorber plate, made up of aluminium. This SAH was compared and tested experimentally against flat plate collector varying the mass flow rates. The cone nets as shown in figure 2 were manufactured and soldered in staggered arrangement to absorber with gas-oxygen. The SAH was inclined at an angle equal to local latitude angle facing due south. The results showed that due conical elements, there was increase in surface area and turbulence which has lead an increase in convective heat transfer between absorber and air causing improvement in the thermal efficiency. At the same time it was found that there was an increase in pressure loss [10].

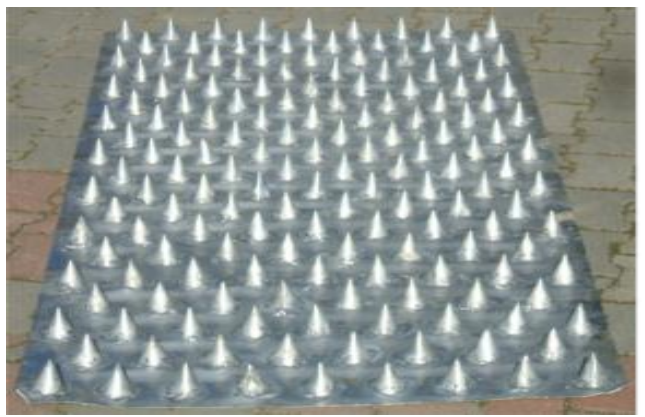

Fig.2- Absorber with conical fins

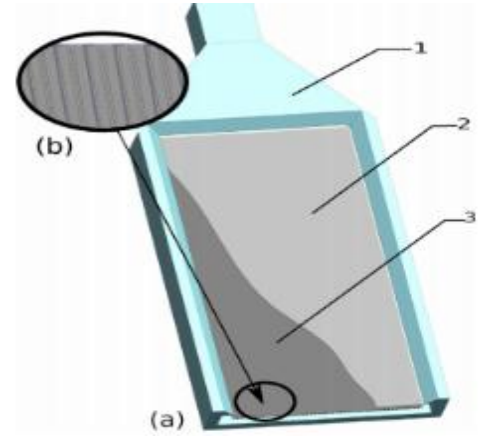

Fig. 3- SAH with duct

M. Cuzminschi et. al designed a portable, light weighted modular air heater system for building sector to achieve comfort conditions which is suitable for green houses and office building. They designed and fabricated a $\mathrm{SAH}$ with a cavity, shown in figure 3 between back insulating part and the solar absorbent which results in decrease of dissipation of thermal energy. In order to increase the efficiency, the flat side of solar absorbent was allowed to face glazing and the radiator-like surface was faced towards insulating back part. The same system was used by the authors to dry the fruits, nuts and seeds when outdoor temperatures were high and there was no need for the heating the building [11].

Ali Heydari et. al carried out their research on SAH having bended absorber, together with flat double blazed cover where air is forced by a blower into helical channels of triangular cross-section as shown in figure 4 . They developed triangular pattern at an angle of $27^{0}$ to the flow path. While experimentation was carried out, the flow was kept in contact with absorber panel via a helical path which increased the time for the flow path. A study was conducted for the improvement of thermal performance with helical path and it was observed that the thermal efficiency increased compared to simple smooth surface absorber and porous surface absorber. It was also found that an increase in flow velocity reduces the difference between input and output temperatures of air heater which increases pressure drops. Pressure fluctuations were observed increased with increasing the flow velocity [12].

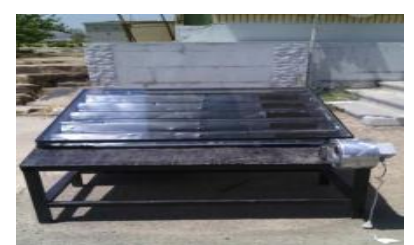

Fig 4 - SAH with helical flow path 


\section{International Journal of Innovations in Engineering and Science, www.ijies.net}

Cristiana V. Croitoru et. al designed an unglazed transpired solar collector which is made up of metal cladding with perforations as shown in figure 5. Round and cross shape geometries were developed by the researchers as shown in figure 5. A metal halide flood light was simulated with $500 \mathrm{~W}$ lightning source at a distance of $45 \mathrm{~cm}$ from collector.
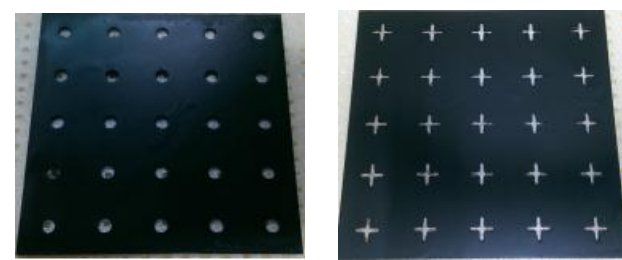

Fig 5- SAH with round and cross perforation

It was found that there was an almost $40 \%$ increase in heat transfer between the perforated cladding and the exhausted air flow [13].

Alsanossi M. Aboghrara et.al as shown in fig 6 developed a $\mathrm{SAH}$ to investigate outlet temperature and efficiency with the effect of circular jet impingement on the corrugated absorber plate. The jets are directed through the holes of the jet plate which impinge on the lower surface of the corrugated absorber plate. After experimental investigations, it was found that the mass flow rate of air substantially influence the heat transfer and increases the efficiency due to breakage of laminar sub-layer, responsible for turbulence [14].
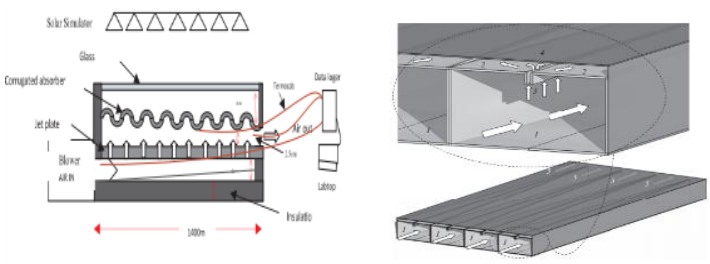

\section{Fig.6-SAH with Corrugated Fig.7 Novel Micro-jet Absorber $S A H$}

M. Zukowski carried out his research on forced SAH with single slot of air impingement on the flat absorber plate as shown in figure 7. The set up consisted with two parallel air ducts in the shape of a triangular prism that are physically separated from one another. The experimentation showed that micro-jet was an effective technique to increase heat transfer and played decisive role for enhancing efficiency. It was also demonstrated that this design results in reduction of operating cost and pressure loss [15].
T. Rajaseenivasan et. al designed and conducted investigations on an impinging jet $\mathrm{SAH}$ which contains the nozzles to distribute the air in SAH as shown in fig 8. The angle of attack was varied at $0^{\circ}, 10^{\circ}, 20^{\circ}, 30^{\circ}, 60^{\circ}$ and $90^{\circ}$ with varying nozzle diameter and flow rates. It was concluded that the highest performance was achieved with $30^{\circ}$ angle of attack and the lowest one was with $0^{0}$ attack. It was also revealed that as the jet diameter decreases, pressure loss also increases [16].

A research as shown in figure 9 was carried out to investigate the thermal performance of SAH consisting of aluminium cane air with and without fins by $G$. Murali et. al. A rigorous experimentation was conducted to investigate the effect of rectangular fins around aluminium cane in absorber plate to enhance the efficiency. It was concluded that the efficiency was improved significantly for air flow rate $0.022 \mathrm{~kg} / \mathrm{s}$ [17].

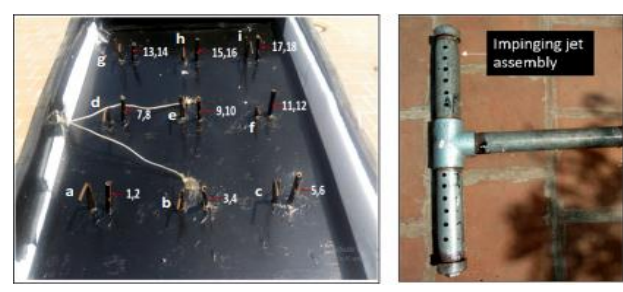

Fig 8-Schematic of Jet Impingement

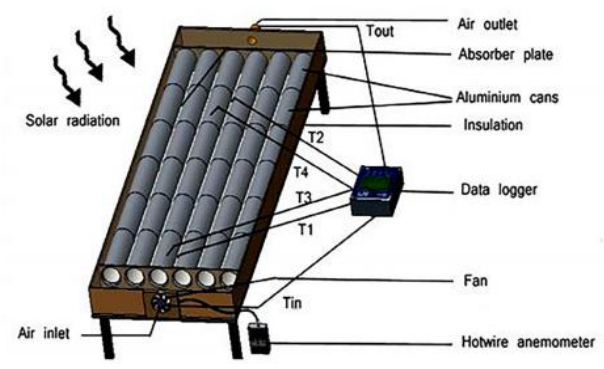

Fig 9 - Solar Air Heater

Investigations on single and double pass $\mathrm{SAH}$ were performed by L.B.Y. Aldabbagh to evaluate the thermal performance of air heater with steel wire mesh layers (packed bed) which behave as a porous media without absorber plate. The experimental study was carried out to analyse the effect of mass flow rate on the outlet temperature and thermal efficiency. It was revealed that the efficiency of the double pass was higher than that of single pass collector depending upon flow rate [18].

Irfan Kurtabas et. al experimentally investigated the effect of free and fixed SAH on efficiency and exergy. The two collectors designed: One composed of rectangular free fins on its below surface through 


\section{International Journal of Innovations in Engineering and Science, www.ijies.net}

hinges and allowed to hang free (Figure 10) while the other was with fixed rectangular fins through soldering. In the experimentation it was found that fixed fin collector was more effective than free fin collector. Fixed fin found with increased outlet temperature of air and pressure drop. It was also found that the free fins worked only as a resistance changed flow lines due to hanging nature which was responsible for decrease in pressure drop [19].

An experimental performance evaluation was carried out by faith Bayrak et. al on porous baffles made up of closed cell aluminium foams, inserted SAH. The thickness was varied for the porous baffles which were placed sequentially and staggered manner as indicated in figure 11.The results showed that the efficiency of solar air collector increases depending upon surface geometry, absorber plate and air mass flow rate. The results also revealed that the efficiencies of the obstacles collector were higher than those without obstacles [20].

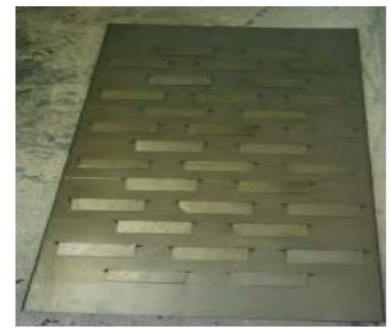

Fig. 10- Absorber with free fins

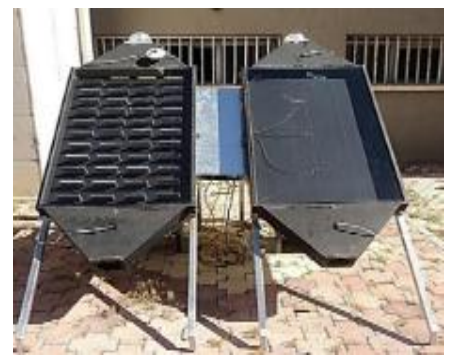

Fig.11-Set up with porous baffles

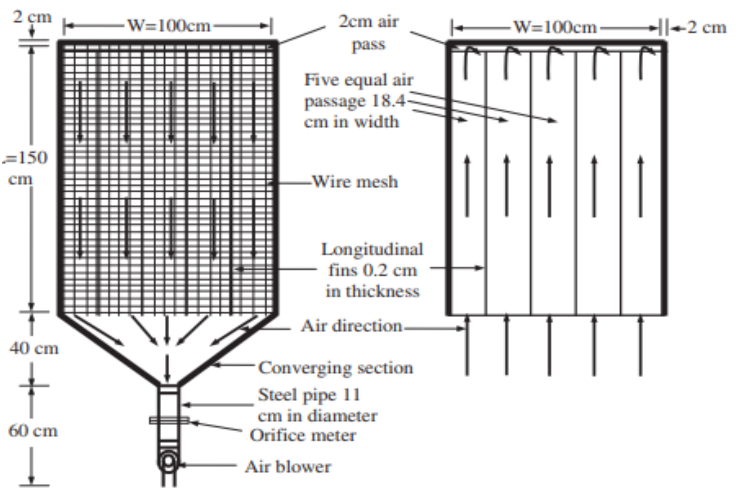

Fig 12-SAH with steel mesh layer
A SAH with single and double pass flow with fins and steel wire mesh as absorber as shown in figure 12 was designed and experimentally evaluated by A P Omojaro et.al. Four metallic fins were arranged longitudinally over which black painted steel wire mesh was fitted which acted as an absorber. This study showed that there was significant increase in the thermal efficiency with the use of low cost and readily available wire mesh absorber plate [21].

\section{CONCLUSION}

The aim of the present review to study the various designs of solar collectors in order to improve efficiency. Solar air heater is a simple device which captures the solar energy. Producing hot air by using solar air heater is a renewable energy heating technology used to process heat generation for space heating and domestic applications. Minimum maintenance like cleaning of collectors only is required. Energy storage not only plays an important role in conservation of the energy but also improves the performance and reliability. A lot of experimentation were carried out to enhance the performance of SAH. Researchers have tried to derive maximum heat from the absorber. The various models that were used for economic analysis of SAHs as a criterion, not only for deciding whether to build a solar energy system, but also for optimizing their design were discussed.

Based on the above review, it can be concluded that:

- As the mass flow rate increases, the efficiency increases and vice-a-versa. The leakages also increase.

- Use of fins and baffles is responsible for increased heat transfer rate and enhances the performance.

- Absorber plate geometry plays key role in the thermal performance of SAH

- Selection of optimum parameters for materials, air mass flow rate, and velocity decide the efficiency.

\section{REFERENCES}

[1]. Hussain Akhtar , Arif Sayed Md, Aslam Md., "Emerging renewable and sustainable energy technologies: State of the art." Renewable and sustainable energy reviews 2017;71: 12-28.

[2]. Hakan F. Oztop, Fatih Bayrak, Arif Hepbasli, "Energetic and exergetic aspects of solar air heating (solar collector) systems" Renewable and Sustainable Energy Reviews 2013;21: 59-83.

[3]. Vanderhulst $P$, Lanser $H$, Bergmeyer P, Foeth $F$, Albers R. "Solar energy: small scale applications in developing countries". Amsterdam, Holland: Stichting Tool; 1990 


\section{International Journal of Innovations in Engineering and Science, www.ijies.net}

[4]. Close DJ. Solar air heaters. "Solar Energy" 1963;7:117-29.

[5]. Varun, Saini RP, Singal SK. "A review on roughness geometry used in solar air heaters" Solar Energy 2007;81:1340-50.

[6]. Alkilani MM, Sopian K, Sohif M, Alghol M. "Output air temperature prediction in a solar air heater integrated with phase change material" European Journal of Scientific Research 2009;27:334-41.

[7]. Pitz-Paal R. "Concentrating solar technologies - the key to renewable electricity and prosee heat for a wide range of application" In:CD-proceedings of the World Renewable Energy Congress VII (WREC 2002). 2002.

[8]. Oztop HF, Bayrak F, Hepbasli A. "Energetic and exergetic aspects of solar air heating (solar collector) systems" Renew Sust Energy Rev 2013;21:59-83.

[9]. Abhishek Saxena, Varun, A.A. El-Sebaii. "A thermodynamic review of solar air heater" Renewable and Sustainable Energy Reviews 2015;43: 863-890.

[10]. Mesut Abuska, "Energy and exergy analysis of solar air heater having new design absorber plate with conical surface" Applied Thermal Engineering 2018;131:115-124

[11]. M. Cuzminschi, R. Gherasima, V. Girleanua, A. Zubareva, I. Stamatina, "Innovative thermo-solar air heater" Energy and buildings (2018);158:964-970

[12]. Ali Heydaria, Mehrdad Mesgarpourb, "Experimental analysis and numerical modeling of solar air heater with helical flow path". Solar Energy (2018);162:278-288

[13]. Cristiana V. Croitoru, Ilinca Nastase, Florin I. Bode, Amina Meslem, "Thermodynamic investigation on an innovative unglazed transpired solar collector" Solar Energy (2016);131:21-29

[14]. Alsanossi M. Aboghraraa, B.T.H.T. Baharudin, M.A. Alghoul, Nor Mariah Adam, A.A. Hairuddin, Husam A. Hasan, "Performance analysis of solar air heater with jet impingement on corrugated absorber plate.case studies in Thermal Engineering" (2017);10:111-120

[15]. M. Zukowski, "Experimental investigations of thermal and flow characteristics of a novel microjet air solar heater". Applied Energy (2015);142:10-20

[16]. T. Rajaseenivasan, S. Ravi Prasanth, M. Salamon Antony, K. Srithar, "Experimental investigation on the performance of an impinging jet solar air heater" Alexandria Engineering Journal (2016).

[17]. G. Murali, A.T.M. Sundari, S. Raviteja, S. Chanukyachakravarthi, M. Tejpraneeth, "Experimental study of thermal performance of solar aluminium can air heater with and without fins materials today(2020) 21:223-230
[18]. L.B.Y. Aldabbagh, F. Egelioglu,M. Ilkan, "Single and double pass solar air heaters with wire mesh as packing bed". Energy (2010);35:3783-3787

[19]. Irfan KURTBAS and Emre TURGUT "Experimental Investigation of Solar Air Heater with Free and Fixed Fins: Efficiency and Exergy Loss" International Journal of Science \& Technology (2006); 1: 75-82

[20]. Fatih Bayrak, Hakan F. Oztop, Arif Hepbasli, "Energy and exergy analyses of porous baffles inserted solar air heaters for building applicationS", Energy and Buildings (2013); 57: 338-345

[21]. A.P. Omojaro, L.B.Y. Aldabbagh, "Experimental performance of single and double pass solar air heater with fins and steel wire mesh as absorber" Applied Energy (2010); 87: 3759-3765 